\title{
The impact of environmental and demographic factors on nursing job satisfaction
}

\author{
Farnaz Rahnavard ${ }^{1}$, Ahmad Kalateh Sadati ${ }^{2}$, Sorror Hemmati ${ }^{3}$, Najmeh Ebrahimzade ${ }^{4}$, Yaser Sarikhani ${ }^{5}$, Seyed
} Taghi Heydari ${ }^{6}$, Kamran Bagheri Lankarani ${ }^{7}$

${ }^{1}$ M.Sc., Institute of Health, Health Policy Research Center, Shiraz University of Medical Sciences, Shiraz, Iran

${ }^{2}$ Ph.D. of Sociology, Assistant Professor, Department of Sociology, Faculty of Social Sciences, Yazd University, Yazd, Iran

${ }^{3} \mathrm{Ph} . \mathrm{D}$. Candidate of Management, Department of Education, Yazd, Yazd, Iran

${ }^{4}$ M.Sc., Institute of Health, Health Policy Research Center, Shiraz University of Medical Sciences, Shiraz, Iran

${ }^{5}$ M.Sc., Research Center for Social Determinants of Health, Jahrom University of Medical Sciences, Jahrom, Iran

${ }^{6} \mathrm{Ph} . \mathrm{D}$. of Biostatistics, Institute of Health, Health Policy Research Center, Shiraz University of Medical Sciences, Shiraz, Iran

${ }^{7}$ Professor of Internal Medicine, Institute of Health, Health Policy Research Center, Shiraz University of Medical Sciences, Shiraz, Iran

\section{Type of article: Original}

\begin{abstract}
Objective: This study aims to evaluate all aspects of job satisfaction in registered nurses working in different hospitals in Shiraz, Iran.

Methods: This cross-sectional study was performed during February to August 2015 in Shiraz, Iran. It comprised of 371 registered nurses working in government and private hospitals using multi-stage cluster sampling. Job satisfaction was evaluated using 5 items of the Job Descriptive Index (JDI) consisting of 63 questions developed by Smith, Kendall, and Hulin (1969). Statistical tests including independent sample $t$ test and one-way analysis of variance (ANOVA) were used in order to identify the relation between job satisfaction, and demographic features and work environment. Data were analyzed by SPSS version 15.0, using descriptive statistics, independentsamples t-test, and ANOVA.

Results: Our findings showed no relationship between demographic variables and job satisfaction. However, a significant association was observed between environmental aspects such as work rotation (fixed versus rotating) nurse's status (staff vs. supervisors), type of hospitals (governmental vs. private) and work $(\mathrm{p}<0.01)$, promotion $(\mathrm{p}<0.02)$ and pay $(\mathrm{p}<0.01)$ items respectively; however, type of hospital was deemed exempt regarding promotion. Also regarding the number of shifts per week, nurses with more than eight shifts present a lower mean score of satisfaction about pay significantly $(\mathrm{p}=0.03)$.

Conclusion: The results concerning younger nurses have different types of satisfaction based on several environmental factors. Nurses' policy makers must pay more attention to nurses' satisfaction and focus on reducing the various inequalities.
\end{abstract}

Keywords: Job Satisfaction, Nurse, Hospitals, Iran

\section{Introduction}

Job satisfaction depicts how content an individual is with his or her employment (1). The traditional model of job satisfaction concentrates on every one of the emotions that an individual has about his/her employment (2). The level of satisfaction of an employee reflects his/or her behavior and attitude towards the job and the degree of commitment to the organization concerned $(3,4)$, and affects citizenship and in-role behavior (5). The main theory

\section{Corresponding author:}

Dr. Seyed Taghi Heydari, Institute of Health, Health Policy Research Center, Shiraz University of Medical Sciences, Shiraz, Iran. Tel.: +98.7132309615, Email: heydari.st@gmail.com

Received: September 03, 2016, Accepted: April 09, 2018, Published: April 2018

iThenticate screening: March 20, 2018, English editing: April 14, 2018, Quality control: April 15, 2018

This article has been reviewed / commented by three experts

(C) 2018 The Authors. This is an open access article under the terms of the Creative Commons Attribution-NonCommercialNoDerivs License, which permits use and distribution in any medium, provided the original work is properly cited, the use is non-commercial and no modifications or adaptations are made. 
that is related to job satisfaction is Maslow's five-level hierarchy. The hypothesis recommends that human needs, frame a five-level progressive system comprising of: physiological needs, security, belongingness/love, regard, and self- actualization $(1,2,6)$. According to Maslow, the fundamental needs of an individual include air, food, clothing, and shelter which are crucial for survival or physiologic needs (6). But human needs do not stop at this level and second to fulfilling the level 1 needs, humans think about security and further necessities of high demand. Another main approach in job satisfaction is Herzberg's motivator-hygiene theory also called the two-factor theory, which represents a number of motivations. These include challenging work, recognition of one's achievement, responsibility, opportunity to do something meaningful, involvement in decision making, sense of importance to an organization which leads to positive satisfaction and status, job security, salary, fringe benefits, work conditions, good pay, paid insurance, vacations are hygiene factors, which occur if there is no job satisfaction $(7,8)$. Generally, this theory is based on two hypotheses that include the following factors: 1) those causing positive job attitudes that are different from factors creating negative attitudes; 2) the factors and the performance or personal effects have association with sequences of job events over a long time period differ from those of short duration (9). This theory underscores the enrichment of employees (10). The healthcare system as a broad organization is affected by job satisfaction (11-13). One component in this system is nursing care which is the focus of extensive studies and associated with potential labor shortages that affect patient care and its accompanying costs (13), quality of care (14, 15 ) burnout $(7,16)$, and intent to leave work $(17,18)$. Nursing is recognized as one of the professions that is highly susceptible to burnout $(19,20)$ and job dissatisfaction (7). Recent studies showed that job satisfaction is associated with age $(13,21)$, length of experience $(21,22)$, marital status (22) and pay (18). Also, it has been shown that workto-family conflict has a mediating role between job satisfaction and turnover intention (23). However, there is little knowledge about the relationship between satisfaction and environmental factors in Iran. In this study, we aim to evaluate association between aspects of job satisfaction and demographic and environmental characteristics in registered nurses in Shiraz, Iran.

\section{Material and Methods}

\subsection{Research design and participants}

This is a cross sectional study that was done in Shiraz, Iran from February to August 2015. The participants included registered nurses in governmental and private hospitals. The study population in this study included all of the nurses working in all of the wards in both government and private hospitals in Shiraz, Iran. According to a report provided by the Department of Nursing at Shiraz University of Medical Sciences, nearly 6,500 nurses were currently working at hospitals in this city. According to the table defined by Morgan and Krejcie (24), 371 subjects were selected for the study. Multi-stage cluster sampling of 6 governmental (with 6 wards) and 5 private hospitals (with 5 wards) were done. The main inclusion criteria was that all nurses except those who had work experience less than one year were included in the study.

\subsection{Instrument and data collection}

The data were collected using two questionnaires, one including demographic features and the other, job environment. The Job Satisfaction questionnaire was a customized inventory produced according to Job Descriptive Index (JDI) developed by Smith, Kendall, and Hulin (1985) (25) where job satisfaction included 5 separate items as work, pay, promotion, opportunities, co-workers, and supervision $(26,27)$. According to JDI, job satisfaction was determined by measuring satisfaction through 5 aspects comprising job, the quality of work (22 items), pay ( 9 items), promotion ( 7 items), supervision (14 items) and co-workers (11 items). The items are presented as statements evaluated by marking the alternative that seems closest to one's experience on a scale from 1 to 5 . The lowest (dissatisfied) and the highest (very satisfied) satisfaction scores were presented as 1 and 5, respectively. Internal validity of 5 aspects were checked and results presented as $0.890,0.956,0.889,0.952$, and 0.892 , respectively. For ensuring validity, face validation was also used. Two MSs were responsible for collecting data. They distributed the questionnaires and nurses completed them.

\subsection{Data analysis}

The analysis of data were conducted by SPSS version 15 (SPSS Inc., Chicago, Illinois, USA), using descriptive statistics (mean and standard deviations), independent-sample t-test (in order to compare sex, marital status, rotating shift work, type of hospital and total job satisfaction), and ANOVA (in order to compare age groups, education levels, work experiences, and type of wards with total burnout and subgroups scores). A two-tailed p-value less than 0.05 was considered as the level of statistical significance. 
http://www.ephysician.ir

\subsection{Research ethics}

Ethical principles of Helsinki declaration and American Sociology Association were considered in this study and the ethics committee of the institute approved the study (Ref. no.: 93-01-01-8365).

\section{Results}

Results showed that 371 people participated in this study, of whom $40(18.9 \%)$ were males and $331(81.1 \%)$ were females. Regarding training, 24 (8.6\%) individuals had completed high school as nursing assistants, 337 persons $(85.3 \%)$ held a bachelor's degree, and $16(5.8 \%)$ had a master's degree. In addition, results showed $169(61 \%)$ people were married and $107(36.6 \%)$ persons were single, while only one $(0.4 \%)$ person was divorced. Table 1 shows that the mean and standard deviation of job satisfaction items, which include work, supervision, co-worker, promotion, and pay are $58.5 \pm 16.9,53.8 \pm 12.8,37.8 \pm 9.8,16.9 \pm 7.7,19.4 \pm 7.8$, and $18.6 \pm 7.0$, respectively. Results showed that there was no association between demographic factors and job satisfaction (Table 1). Regarding environmental factors, results showed that there was significant association between rotating shift and work $(\mathrm{p}=0.008)$, promotion $(\mathrm{p}=0.02)$ and pay $(\mathrm{p}=0.01)$ items of job satisfaction, where the score of nurses with fixed shift $(64.5 \pm 15.0)$ was higher than that of nurses with rotating shift $(57.3 \pm 16.9)$. There was significant association between status at work (staff or supervision) and work $(\mathrm{p}=0.001)$, promotion $(\mathrm{p}<0.001)$ and pay $(\mathrm{p}=0.001)$ items of job satisfaction. In this item, staff nurses gained less score (56.7 \pm 17.0$)$ than supervisors $(64.9 \pm 13.3)$. Regarding the number of shifts per week it was in association with the pay item $(\mathrm{p}=0.03)$. As for type of hospital (governmental vs. private), there was association with work $(\mathrm{p}=0.01)$ and pay $(\mathrm{p}<0.001)$ items. In this variable, nurses of private hospitals had more score $(62.5 \pm 17.8,21.4 \pm 6.7)$ than those in governmental hospitals $(57.2 \pm 16.4,17.7 \pm 6.9)$ respectively, to work and pay items.

Table 1. Association between demographic factors and job satisfaction items

\begin{tabular}{|c|c|c|c|c|c|c|c|c|c|c|c|}
\hline \multirow{2}{*}{\multicolumn{2}{|c|}{ Demographic factors }} & \multirow{2}{*}{\multicolumn{10}{|c|}{ Job satisfaction items }} \\
\hline & & & & & & & & & & & \\
\hline & & Mean & SD & Mean & SD & Mean & SD & Mean & SD & Mean & SD \\
\hline \multirow[t]{3}{*}{ Age (year) } & $20-29$ & 59.0 & 16.4 & 53.2 & 12.5 & 38.4 & 9.5 & 17.1 & 7.3 & 19.9 & 8.0 \\
\hline & $30-39$ & 57.0 & 16.8 & 54.3 & 13.2 & 37.1 & 9.4 & 16.6 & 7.9 & 19.5 & 7.7 \\
\hline & $>40$ & 60.0 & 17.3 & 56.0 & 12.1 & 38.7 & 10.4 & 17.5 & 8.2 & 18.8 & 7.6 \\
\hline \multicolumn{2}{|l|}{ p-value } & \multicolumn{2}{|l|}{0.498} & \multicolumn{2}{|l|}{0.450} & \multicolumn{2}{|l|}{0.443} & \multicolumn{2}{|l|}{0.736} & \multicolumn{2}{|l|}{0.719} \\
\hline \multirow[t]{2}{*}{ Sex } & Male & 57.8 & 58.5 & 51.0 & 54.6 & 39.9 & 37.7 & 15.6 & 17.2 & 18.7 & 19.6 \\
\hline & Female & 19.9 & 16.3 & 14.8 & 12.3 & 10.2 & 9.6 & 8.0 & 7.6 & 8.9 & 7.7 \\
\hline \multicolumn{2}{|l|}{$p$-value } & \multicolumn{2}{|l|}{0.795} & \multicolumn{2}{|l|}{0.072} & \multicolumn{2}{|l|}{0.147} & \multicolumn{2}{|l|}{0.183} & \multicolumn{2}{|l|}{0.456} \\
\hline \multirow[t]{3}{*}{ Education } & $\begin{array}{l}\text { High school } \\
\text { graduate }\end{array}$ & 60.2 & 17.5 & 52.4 & 14.4 & 36.0 & 10.3 & 17.5 & 6.1 & 19.3 & 6.8 \\
\hline & Bachelor degree & 58.4 & 16.7 & 54.2 & 12.6 & 38.1 & 9.8 & 17.0 & 7.8 & 19.5 & 7.9 \\
\hline & Master degree & 55.5 & 19.3 & 50.0 & 14.1 & 36.6 & 10.1 & 14.9 & 8.3 & 18.8 & 8.9 \\
\hline \multicolumn{2}{|l|}{$p$-value } & \multicolumn{2}{|l|}{0.673} & \multicolumn{2}{|l|}{0.340} & \multicolumn{2}{|l|}{0.456} & \multicolumn{2}{|l|}{0.452} & \multicolumn{2}{|l|}{0.928} \\
\hline \multirow[t]{2}{*}{ Marital status } & Married & 58.7 & 17.0 & 53.8 & 13.5 & 37.0 & 9.8 & 16.9 & 7.8 & 19.2 & 7.6 \\
\hline & Single & 57.4 & 16.5 & 54.2 & 11.5 & 39.0 & 9.7 & 16.6 & 7.5 & 19.7 & 8.2 \\
\hline \multicolumn{2}{|l|}{$p$-value } & \multicolumn{2}{|l|}{0.502} & \multicolumn{2}{|l|}{0.777} & 0.079 & & 0.716 & & 0.631 & \\
\hline Work experience & $\leq 5$ & 57.6 & 14.7 & 53.1 & 12.4 & 38.1 & 9.3 & 17.0 & 6.7 & 19.4 & 7.3 \\
\hline (year) & $6-15$ & 57.7 & 18.2 & 54.0 & 12.9 & 37.2 & 9.8 & 16.2 & 8.1 & 19.6 & 8.4 \\
\hline & $>15$ & 62.7 & 18.4 & 54.7 & 13.3 & 38.2 & 10.1 & 18.5 & 8.5 & 19.4 & 7.6 \\
\hline $\mathrm{p}$-value & & 0.180 & & 0.724 & & 0.693 & & 0.199 & & 0.963 & \\
\hline
\end{tabular}

Statistical method: independent-samples t-test was done for examining association between job satisfaction items and sex and marital status. In addition, one-way ANOVA was used for examining the association between job satisfaction items and age, education, and work experience (years). ${ }^{*} \mathrm{p}<0.05 .{ }^{* *} \mathrm{p}<0.01$ 
Table 2. Association between environmental variables and job satisfaction items

\begin{tabular}{|c|c|c|c|c|c|c|c|c|c|c|c|}
\hline \multirow{3}{*}{\multicolumn{2}{|c|}{ Demographic factors }} & \multicolumn{10}{|c|}{ Job satisfaction items } \\
\hline & & \multicolumn{2}{|c|}{ Work } & \multicolumn{2}{|c|}{ Supervision } & \multicolumn{2}{|c|}{$\begin{array}{l}\text { Co- } \\
\text { workers }\end{array}$} & \multicolumn{2}{|c|}{ Promotion } & \multicolumn{2}{|l|}{ Pay } \\
\hline & & Mean & SD & Mean & SD & Mean & SD & Mean & SD & Mean & SD \\
\hline \multirow[t]{2}{*}{ Rotating shift work } & Fix & 64.5 & 15.0 & 54.3 & 12.6 & 37.6 & 10.5 & 19.2 & 7.7 & 22.0 & 7.3 \\
\hline & Rotation & 57.3 & 16.9 & 53.9 & 12.9 & 38.0 & 9.6 & 16.5 & 7.6 & 19.0 & 7.8 \\
\hline \multicolumn{2}{|l|}{ p-value } & \multicolumn{2}{|c|}{$0.008^{* *}$} & \multicolumn{2}{|l|}{0.859} & \multicolumn{2}{|l|}{0.770} & \multicolumn{2}{|l|}{0.022} & \multicolumn{2}{|c|}{$0.016^{*}$} \\
\hline \multirow[t]{2}{*}{ Status at work } & Staff & 56.7 & 17.0 & 53.4 & 13.0 & 37.7 & 9.7 & 16.1 & 7.3 & 18.9 & 7.6 \\
\hline & Supervision & 64.9 & 13.3 & 55.0 & 12.7 & 37.7 & 10.4 & 20.3 & 7.9 & 22.7 & 7.1 \\
\hline \multicolumn{2}{|l|}{$\mathrm{p}$-value } & \multicolumn{2}{|c|}{$0.001 * *$} & \multicolumn{2}{|l|}{0.404} & \multicolumn{2}{|l|}{0.992} & \multicolumn{2}{|c|}{$<0.001 * *$} & \multicolumn{2}{|c|}{$0.001^{* *}$} \\
\hline \multirow[t]{4}{*}{ Type of ward } & Emergency & 59.0 & 19.7 & 51.1 & 12.3 & 39.2 & 10.9 & 18.0 & 8.5 & 21.3 & 10.0 \\
\hline & ICU or CCU & 56.5 & 16.3 & 54.2 & 13.2 & 37.8 & 9.1 & 16.4 & 7.4 & 19.5 & 8.0 \\
\hline & Internal & 55.3 & 15.7 & 51.7 & 12.8 & 36.3 & 9.5 & 16.7 & 7.8 & 17.3 & 6.1 \\
\hline & Surgery & 61.5 & 16.4 & 55.4 & 12.6 & 37.7 & 10.9 & 16.6 & 7.9 & 18.5 & 6.8 \\
\hline \multicolumn{2}{|l|}{$\mathrm{p}$-value } & \multicolumn{2}{|l|}{0.128} & \multicolumn{2}{|l|}{0.235} & \multicolumn{2}{|l|}{0.647} & \multicolumn{2}{|l|}{0.661} & \multicolumn{2}{|l|}{0.105} \\
\hline \multirow{3}{*}{$\begin{array}{l}\text { Number of shift per } \\
\text { week }\end{array}$} & $\leq 6$ & 60.9 & 16.7 & 53.7 & 14.0 & 36.5 & 10.6 & 17.4 & 8.0 & 20.5 & 7.8 \\
\hline & $6-8$ & 57.3 & 15.9 & 53.4 & 11.9 & 38.1 & 9.2 & 16.8 & 7.5 & 19.4 & 7.8 \\
\hline & $>8$ & 59.8 & 21.3 & 58.2 & 15.8 & 40.6 & 10.2 & 16.5 & 7.7 & 15.8 & 5.9 \\
\hline \multicolumn{2}{|l|}{$p$-value } & \multicolumn{2}{|l|}{0.267} & \multicolumn{2}{|l|}{0.195} & \multicolumn{2}{|l|}{0.161} & 0.792 & & 0.034 & \\
\hline Type of hospital & $\begin{array}{l}\text { Government } \\
\text { hospitals }\end{array}$ & 57.2 & 16.4 & 54.1 & 12.9 & 37.7 & 10.3 & 16.5 & 7.4 & 18.3 & 7.1 \\
\hline & Private hospitals & 62.5 & 17.8 & 53.0 & 12.8 & 38.1 & 8.4 & 18.1 & 8.3 & 22.6 & 9.1 \\
\hline $\mathrm{p}$-value & & $0.019^{*}$ & & 0.467 & & 0.732 & & 0.094 & & $<0.00$ & \\
\hline
\end{tabular}

Statistical method: independent sample $t$ test was done for examining association between job satisfaction items and rotating shift work, status at work, and type of hospital. In addition, one-way ANOVA was used for examining the association between job satisfaction items and type of ward and number of shift per week. ${ }^{*} \mathrm{p}<0.05 .{ }^{* *} \mathrm{p}<0.01$

\section{Discussion}

In this study, we aimed to evaluate the relation between demographic and environmental variables and 5 job satisfaction scales in Shiraz, Iran. Results showed that not all demographic variables such as age, sex, education, work experience, and marital status were associated with job satisfaction scales, thus rejecting the first hypothesis. This finding is comparable with findings of Purpora and Blegen, which showed no statistically significant differences in job satisfaction between gender ethnicity, basic registered nurse education, highest degree held, size of hospital or clinical field (28). In regard to demographic variables, the results of several studies are consistent with our findings. Significant association has been demonstrated between age, length of service, and marital status and job satisfaction among Chinese nurses (22). Also, there were relationships between job satisfaction and length of career in Korean nurses working in an emergency medical center (21), and between job satisfaction and age among nurses in Oman (13). The reasons behind this discrepancy may be that job satisfaction in this study is related to environmental factors more significantly than to demographic variables. On the other hand, job satisfaction is related to organization characteristics and specifically to relationship between nurses and their work, supervisors, opportunities and job benefits. As mentioned, evaluation of environmental variables showed significant association between quality of shift work, work status, the number of shifts per week, job, promotion and the pay scales. Nurses with fixed rotation and supervision status have significantly higher job score, promotion and pay compared to nurses on shift rotation and staff position. On the other hand, a relationship was observed between the number of shifts per week and pay scale. In this connection, the nurses who covered more than eight shifts per week had lower score in pay than those having less shifts. In the context of study nurses with fixed shifts, supervision status and equal or less than six shifts are included in managers group. The people in this group not only have more opportunities in the system but also have higher salary and benefits. They also have hidden benefits enabling them to plan for their future, take holidays, and enjoy environmental privileges. Because of having no night shift, they have less psychological problems than other nurses. Therefore, nurses on fixed shifts, specifically morning shifts, have high opportunities regarding pay, promotion and other environmental privileges. In this context, significant differences in job, pay and promotion create basic inequity and dissatisfaction among nurses. In other words, those who work more have less benefits and salary. On the other hand, job status has a similar situation to work rotation shift. In this variable, the higher the position leads to a higher job level, promotion and pay. Supervision status has a high score in 
job satisfaction scales. Concerning the number of shifts per week, results showed that the nurses with more than eight shifts per weeks have significantly less mean score in pay. And finally, results showed that nurses in governmental hospital have significantly less mean score in relation to job, promotion and pay than those working in private hospitals. Considering these findings, job satisfaction is determined by salary and benefits. Results in this part are comparable to some and incomparable to other variables reported by several studies. They showed association between shift work (12), pay (18) extrinsic rewards (12) and job satisfaction among nurses. On the other hand, another study in a nursing school showed that salary is a significant indicator of job satisfaction (29), although no significant relationship was found between gender and job satisfaction (28). Contrary to our findings, several studies showed that other variables such as age $(12)$ work experience $(21,22)$ marital status $(22)$ peer relationship (28) and demographic variables (29) were associated with job satisfaction. The results showed that regarding job, promotion and pay, nurses of governmental hospitals had significantly less mean score than those in private hospitals. It is also known that pay in governmental hospitals is higher than that of private hospitals. Nurses in private hospitals have a prejudice; their salaries are set according to law, while governmental nurses expect to have benefits proportionate to physicians. Therefore, we can conclude that inequity is the main problem of nurses in governmental hospitals, and influences their dissatisfaction. It is recommended to conduct more research in this regard. According to discussion on a theoretical level, it can be said that environmental factors in Herzberg's theory more emphatically refer to the hygienic elements as do physiological needs in Mazola's view. On the other hand, inequity, which was significantly shown in relation to governmental nurses, corresponds to higher-level needs in Mazola's view. Accordingly, nurses in governmental hospitals engage in the healthcare system, and believe that an unequitable system results from unequal distribution of opportunities and benefits. 5- Limitation and recommendation: The main limitation of this study was that it was carried out shortly before designing the Ghasedak plan, aimed to redefine the payment system for all employees in governmental hospitals, where the first payment of the new plan was paid to nurses following the release of the result of this study in Jul 2015. Despite the rise in salary, the inequality was evident among nurses' groups including staff nurses, supervisors, and nursing assistants. Therefore, further study is warranted to introduce a new plan in relation to benefit and payment.

\section{Conclusions}

The findings of this research indicated an association between some environmental characteristics and job satisfaction. Significant relationship was found between the type of rotation shift, nurses' status and governmental registration and work, pay and promotion. Also, nurses with more than eight shifts per week, gain significantly less score in pay, a situation demanding the attention of nursing authorities to promote nurses' job satisfaction. On the other hand, healthcare authorities must address inequity in salary and benefits in the healthcare systems to reduce job dissatisfaction among nurses as well as other healthcare providers.

\section{Acknowledgments:}

This research was supported by Grant no. 01-8365 of Health Policy Research Center, Shiraz University of Medical Sciences, Shiraz, Iran.

\section{Conflict of Interest:}

There is no conflict of interest to be declared.

\section{Authors' contributions:}

All authors contributed to this project and article equally. All authors read and approved the final manuscript.

\section{References:}

1) Kabir MN, Parvin MM. Factors affecting employee job satisfaction of pharmaceutical sector. Australian Journal of Business and Management Research. 2011; 1(9): 113-23.

2) $\mathrm{Lu} \mathrm{H}$, While $\mathrm{AE}$, Barriball KL. Job satisfaction among nurses: a literature review. International journal of nursing studies. 2005; 42(2): 211-27. doi: 10.1016/j.jinurstu.2004.09.003.

3) Griffin RW, Bateman TS. Job satisfaction and organizational commitment. International review of industrial and organizational psychology. New York, NY: Wiley; 1986: 157-188.

4) O'Leary-Kelly AM, Griffin RW. Job satisfaction and organizational commitment. Psychology and policing. 1995; 367: 393.

5) Williams LJ, Anderson SE. Job satisfaction and organizational commitment as predictors of organizational citizenship and in-role behaviors. Journal of management. 1991; 17(3): 601-17. doi: 10.1177/014920639101700305.

6) Freitas FA, Leonard LJ. Maslow's hierarchy of needs and student academic success. Teaching and Learning in Nursing. 2011; 6(1): 9-13. doi: 10.1016/j.teln.2010.07.004. 
7) Aiken LH, Clarke SP, Sloane DM, Sochalski J, Silber JH. Hospital nurse staffing and patient mortality, nurse burnout, and job dissatisfaction. JAMA. 2002; 288(16): 1987-93. doi: 10.1001/jama.288.16.1987. PMID: 12387650.

8) Herzberg F. One more time: How do you motivate employees. New York: The Leader Manager. 1986.

9) Herzberg F. Motivation-hygiene theory. 2005: 61.

10) Paul WJ, Robertson KB, Herzberg F. Job enrichment pays off. Harvard Business Review. 1969; 47(2): 6178.

11) Gui L, Barriball KL, While AE. Job satisfaction of nurse teachers: A literature review. Part I: Measurement, levels and components. Nurse Education Today. 2009; 29(5): 469-76. doi: 10.1016/j.nedt.

12) Maqbali MA. Factors that influence nurses' job satisfaction: a literature review. Nursing management. 2015; 22(2): 30-7. doi: 10.7748/nm.22.2.30.e1297.

13) Van Bogaert P, Van Heusden D, Verspuy M, Wouters K, Slootmans S, Van der Straeten J, et al. The Productive Ward Program. A Two-Year Implementation Impact Review Using a Longitudinal Multilevel Study. Can J Nurs Res. 2017; 49(1): 28-38. doi: 10.1177/0844562116686491.

14) Laschinger HKS, Shamian J, Thomson D. Impact of magnet hospital characteristics on nurses' perceptions of trust, burnout, quality of care, and work satisfaction. Nursing economics. 2001; 19(5): 209.

15) Redfern S, Hannan S, Norman I, Martin F. Work satisfaction, stress, quality of care and morale of older people in a nursing home. Health \& social care in the community. 2002; 10(6): 512-7. doi: 10.1046/j.13652524.2002.00396.x.

16) Kalliath T, Morris R. Job satisfaction among nurses: a predictor of burnout levels. Journal of nursing administration. 2002; 32(12): 648-54. doi: 10.1097/00005110-200212000-00010. PMID: 12483086.

17) Larrabee JH, Janney MA, Ostrow CL, Withrow ML, Hobbs GR, Burant C. Predicting registered nurse job satisfaction and intent to leave. Journal of Nursing Administration. 2003; 33(5): 271-83. doi: 10.1097/00005110-200305000-00003. PMID: 12792282.

18) Coomber B, Barriball KL. Impact of job satisfaction components on intent to leave and turnover for hospital-based nurses: a review of the research literature. International journal of nursing studies. 2007; 44(2): 297-314. doi: 10.1016/j.ijnurstu.2006.02.004. PMID: 16631760.

19) Sadati AK, Rahnavard F, Heydari ST, Hemmati S, Ebrahimzadeh N, Lankarani KB. Health Sector Reform, Emotional Exhaustion, and Nursing Burnout: A Retrospective Panel Study in Iran. J Nurs Res. 2017; 25(5): 368-74. doi: 10.1097/jnr.0000000000000183. PMID: 28877124.

20) Ebrahimzade N, Mooghali A, Lankarani KB, Sadati AK. Relationship Between Nursing Managers' Leadership Styles and Nurses' Job Burnout: A Study at Shahid Dr. Faghihi Hospital, Shiraz, Iran. Shiraz EMedical Journal. 2015; 16(8). doi: 10.17795/semj27070.

21) Park MS, Jeoung Y, Lee HK, Sok SR. Relationships Among Communication Competence, Self-Efficacy, and Job Satisfaction in Korean Nurses Working in the Emergency Medical Center Setting. J Nurs Res. 2015; 23(2): 101-8. doi: 10.1097/jnr.0000000000000059. PMID: 25967640.

22) Ouyang YQ, Zhou WB, Qu H. The impact of psychological empowerment and organisational commitment on Chinese nurses' job satisfaction. Contemporary nurse. 2015: 1-12. doi: 10.1080/10376178.2015.1010253.

23) Chen IH, Brown R, Bowers BJ, Chang WY. Work - to - family conflict as a mediator of the relationship between job satisfaction and turnover intention. Journal of Advanced Nursing. 2015; 71(10): 2350-63. doi: 10.1111/jan.12706.

24) Krejcie RV, Morgan DW. Determining sample size for research activities. Educ Psychol Meas. 1970; 30: 607-10. doi: 10.1177/001316447003000308.

25) Smith PC, Kendall LM, Hulin CL. The measurement of satisfaction in work and retirement. Chicago, IL: Rand McNally; 1969.

26) Hulin CL, Smith PC. Sex differences in job satisfaction. Journal of Applied Psychology. 1964; 48(2): 88. doi: $10.1037 / \mathrm{h} 0040811$.

27) Hulin CL, Smith PC. A linear model of job satisfaction. Journal of Applied Psychology. 1965; 49(3): 209. doi: $10.1037 / \mathrm{h} 0022164$.

28) Purpora C, Blegen MA. Job satisfaction and horizontal violence in hospital staff registered nurses: the mediating role of peer relationships. Journal of clinical nursing. 2015; 24(15): 2286-94. doi: 10.1111/jocn.12818.

29) Moody NB. Nurse faculty job satisfaction: A national survey. Journal of Professional Nursing. 1996; 12(5): 277-88. doi: 10.1016/S8755-7223(96)80007-X. 